\title{
Article \\ Determinants for Smallholder Farmers' Adoption of Improved Forages in Dairy Production Systems: The Case of Tanga Region, Tanzania
}

\author{
Hycenth Tim Ndah ${ }^{1,2} \mathbb{D}^{\mathbb{D}}$, Johannes Schuler ${ }^{1, *(\mathbb{D})}$, Vandoline N. Nkwain ${ }^{3}$, Beatus Nzogela ${ }^{4}$, Walter Mangesho ${ }^{5}$ \\ Richard Mollel ${ }^{5}$, Rose Loina ${ }^{5}$, Peter Zander ${ }^{1}$ and Birthe K. Paul ${ }^{4}$ \\ 1 Leibniz Centre for Agricultural Landscape Research (ZALF), 15374 Müncheberg, Germany; \\ tim.ndah@zalf.de (H.T.N.); zander@zalf.de (P.Z.) \\ 2 Department of Communication and Advisory Services in Rural Areas, University of Hohenheim, \\ 70599 Stuttgart, Germany \\ 3 Freelance Consultant, 67365 Schwegenheim, Germany; meetvandy@yahoo.com \\ 4 International Center for Tropical Agriculture (CIAT), Nairobi P.O. Box 823-00621, Kenya; \\ beatusnzogela6son@gmail.com (B.N.); birthe.paul@giz.de (B.K.P.) \\ 5 Tanzania Livestock Research Institute (TALIRI), Eastern Zone, Tanga P.O. Box 5016, Tanzania; \\ wmangesho81@gmail.com (W.M.); richardmollel38@gmail.com (R.M.); rloina15@gmail.com (R.L.) \\ * Correspondence: schuler@zalf.de
}

Citation: Ndah, H.T.; Schuler, J.; Nkwain, V.N.; Nzogela, B.;

Mangesho, W.; Mollel, R.; Loina, R.;

Zander, P.; Paul, B.K. Determinants for Smallholder Farmers' Adoption of Improved Forages in Dairy Production Systems: The Case of Tanga Region, Tanzania. Agronomy 2022, 12, 305. https://doi.org/ 10.3390/agronomy12020305

Academic Editors: M. Jordana Rivero and Mary Bridget Lynch

Received: 13 December 2021

Accepted: 21 January 2022

Published: 25 January 2022

Publisher's Note: MDPI stays neutral with regard to jurisdictional claims in published maps and institutional affiliations.

Copyright: (C) 2022 by the authors. Licensee MDPI, Basel, Switzerland. This article is an open access article distributed under the terms and conditions of the Creative Commons Attribution (CC BY) license (https:// creativecommons.org/licenses/by/ $4.0 /)$.

\begin{abstract}
Dairy productivity in sub-Saharan Africa remains below its potential, while there is an increasing demand for milk from its growing population. This study focuses on the adoption potential of improved, more nutritive and productive forages by smallholder farmers in the Tanga region of Tanzania. By applying a qualitative mixed-method approach, including farm visits, interviews and a multi-stakeholder workshop guided by the Qualitative Assessment Tool for Forage Technologies (QATo-FT), we systematically identify and analyse the roles of the (i) institutional and political, (ii) socio-economic and (iii) cultural factors influencing the adoption and diffusion of improved forage technologies. The findings reveal the unsuitable cool climate and unfavourable socioeconomic conditions, including low labour opportunity costs in the dry season as critical reasons for the low current adoption rate. However, a positive community attitude, the recognised ecological benefits and the supporting role of promoting institutions are the main influencing factors of a high adoption potential. Yet, the political and institutional framework at the regional level, as well as the market conditions, negatively influence the adoption potential. We suggest an integrated approach for rural development that goes beyond the improvement of yields, but provides more efficient use of land and labour in the region.
\end{abstract}

Keywords: adoption; innovations; forages; Tanzania; qualitative assessment; sub-Saharan Africa

\section{Introduction}

Agriculture is the main economic pillar of most African countries. Being an integral part of many African traditions [1], livestock rearing plays a vital role in sub-Saharan Africa's agricultural practice. The region has a large cattle population of about 191 million heads [2], but dairy productivity remains below potential, partly because the traditional techniques that dominated the sector for decades are still widespread. Jahnke et al. [3] purport that although developing countries (in the 1980s) owned 70\% of the world's bovines (including buffaloes), they only produced $29 \%$ of the global meat and $23 \%$ of the global milk output.

In 2021, Africa's self-sufficiency in dairy products did not change, if anything, it is expected to grow worse as population growth remains high [4]. In contrast, the rapidly growing African population means an increasing demand for dairy products, which is found to largely outweigh their production in Africa $[1,5,6]$. According to Alexandratos 
and Bruinsma [7], the average per-person meat consumption per year in sub-Saharan Africa (SSA) is $10 \mathrm{~kg}$ and is projected to reach $16 \mathrm{~kg} /$ person in 2050, while that of milk consumption stood at $31 \mathrm{~L} /$ person/year in 2005/2007 and is projected to reach $37 \mathrm{~L}$ in 2050. Ndambi et al. [1] highlighted this high demand when they compared the demand growth rate of dairy products in Africa (4.0\%) to their production growth rate (3.1\%) between 1990 and 2004.

These numbers demonstrate that Africa's dairy production capacity is yet to be optimised, and self-sufficiency in dairy production is not attained. Given that a substantial increase in Africa's milk production could yield multiplier effects, such as poverty alleviation, improved nutrition and income generation [8], organisations, such as Heifer Project International, Land O Lakes, Send a Cow, International Livestock Research Institute (ILR(I) and the International Center for Tropical Agriculture (CIAT), have been working on strategies to narrow the gap between the demand and supply of milk and its products in Africa. Some of the main strategies in this respect have been the introduction of better animal breeds and quality feed for livestock. For over fifty years, researchers tested and introduced nutritive and low-cost legumes and fodder shrubs to improve cattle's protein intake and increase the productivity of SSA dairy farms [9-11]. However, their adoption by smallholder livestock farmers has proven to be unsatisfactory. Franzel [12] and Wambugu [11] found that despite the heavy sensitisation on more nutritive forage technologies in East Africa, only $10 \%$ of the smallholder farmers took them up by 2005 . Additionally, the numbers of shrubs planted were largely inadequate.

Poor rates of adoption for improved forage technologies were reported in most parts of SSA where they were introduced (e.g., Malawi [13], Ethiopia [14], Central Kenya [15] as well as Kenya, Uganda and Rwanda [6]. The question remains why improved forage production systems, which hold the potential to greatly improve dairy farm outputs and the livelihoods of farmers, do not seem to gain attention within the targeted communities. Why are smallholder dairy farmers in sub-Saharan Africa and Tanzania, in particular, reluctant towards adopting the forage technologies introduced to improve the performance of the dairy cows? This paper focuses on exploring the avenues for answers to this question. By applying a qualitative mixed-method tool, including farm visits, interviews and a multistakeholder workshop (guided by the Qualitative Assessment Tool for Forage Technologies: QATo-FT), we systematically identify and analyse the roles of the (i) institutional and political, (ii) socio-economic and (iii) cultural factors influencing the adoption and diffusion of improved forage technologies in sub-Saharan Africa with a special focus on the Tanga region (Tanzania) as a case study.

In this study, we define forage technologies as new forage production systems, including new, improved varieties and species. This paper was prepared based on a project report published as a non-peer reviewed working paper, which includes other related elements originally meant to serve the purpose of project reporting [16].

\section{Materials and Methods}

\subsection{Conceptual Basis}

The acceptance of innovations by farmers, widely referred to as "adoption", is seen to be determined by the individual choices farmers make to welcome or turn down the innovation [17]. According to Rogers [18], the adoption decision process is linked to "an information-seeking and information-processing activity, where an individual is motivated to reduce uncertainty about the advantages and disadvantages of an innovation". In particular, such an adoption decision process can be systematically structured by five action steps that an individual goes through, namely (1) knowledge, (2) persuasion, (3) decision, (4) implementation and (5) confirmation [18]. These stages typically follow each other chronologically. In a similar light, Straub [19] states that technology adoption is a complex, inherently social, developmental process, and successfully facilitating technology adoption must address the cognitive, emotional and contextual concerns of the individuals. Ndah [20], Rogers [18], Adesina and Baidu-Forson [21] observed that farmers' ${ }^{\prime}$ perceptions 
of the characteristics of a given technology highly affects their adoption decision. Moreover, Fowler and Rockstrom [22] remarked that the favourable conditions required for adopting new technologies by smallholder farmers must include positive chances of affordability, less complexity, local resource-base and less effect or dependence on peak labour demands. Other studies highlighted the possible mitigating role of such land-based-related technologies (e.g., improved forages) against climate risk as a determining factor for smallholder farmers' adoption decisions [23,24]. Such climate-risk-related adoption decisions could be especially true for farmers perceived to have experienced past production shocks as a result of less certainty in climate patterns.

In short, the adoption of sustainability-oriented innovations generally revolves around the conditional requirements for and around the use of such a technology. In SSA, there exist numerous socio-economic, institutional and ethical factors that contribute to or affect the adoption of such innovations in agriculture. Inspired by the understanding imbued in the above theoretical basis, the factors that determine the adoption of improved forage technologies by small scale farmers can be classified into (i) individual characteristics that predispose an individual farmer to either accept or reject the innovation, (ii) innovation attributes that include its ease of use and compatibility with the community or individual's lifestyle and (iii) contextual characteristics that create the enabling environment or surroundings, within which the individual farmer makes the adoption decision about the innovation. These theoretical bases and thematic classifications are used to frame this study.

\subsection{Methods}

In addition to a literature review that led to obtaining background information on the current state of the adoption of forage technologies in SSA, Tanzania and the case study region, empirical data collection for this study was realised through (i) semi-structured qualitative interviews and (ii) multi-stakeholder focus group discussions directed by the Qualitative Expert Assessment Tool for Forage Technologies (QATo-FT), an adapted version of the Qualitative Expert Assessment tool for Conservation agriculture (QAToCA) [20,25]. By tool, in this case, we refer to a decision support research method that is MS-Excel based, with the questions and indicators thematically integrated, and serves the purpose of guiding a multi-stakeholder discussion as well as generating empirical data for scientific purposes.

\subsubsection{Field Visits and Interviews}

The targeted farmers for the field visits and interviews were sampled as members of the existing innovation platforms in the two villages of Mbuzii-Bumbuli and UbiriLushoto, by the help of village extension officers. These platforms were created under previous projects in the regions and further strengthened under the forage technology project in which this work was realised. In addition to adopting farmers, sceptical farmers were equally identified through the help of peers following a snowball method, then visited and interviewed in the process as we walked across the villages. In total, each interview and field visit lasted about 45-60 min. The aim of the interviews was to make a first appraisal with regard to the adoption decision process of farmers with a focus on identifying the main triggering factors for initial adoption, and reasons for sustaining adoption after the implementation (adoption) decision was made. By triggering factors, we refer to the very first trigger (s) that initiated the farmers' decision to adopt the use of forage technologies. These interviews mainly targeted individual farmers' perspectives on the following questions:

1. What was the source of first knowledge on improved forage technologies?

2. What was the year of this first knowledge?

3. What was the actual starting year, e.g., first planting of materials?

4. What reasons made you start? (trigger)

5. What reasons keep you going on? (supporting forces)

6. At what point did you feel uncomfortable, and if so why? (inhibiting forces) 
7. What recommendations do you have towards the further improvement of this technology as a farmer?

The issues discussed in the interviews were clustered by the participating researchers generating key observations, which were later used for starting the discussion in the QATo-FT multi-stakeholder workshop.

\subsubsection{Qualitative Assessment Tool for Forage Technologies}

In this study, we applied the Qualitative Assessment Tool for Forage Technologies (QATo-FT) to assess the relative likelihood of the adoption of forage technologies under the agro-ecological, socio-economic and cultural conditions of the targeted case study region. As a decision support tool, QATo-FT targets researchers, policy makers, service providers, farmers and all regional stakeholders in their respective promoting organisations focused on enhancing the adoption of improved forage technologies. It is designed for a qualitative assessment of all the factors (mostly at the higher or regional level) that influence the adoption of new forage technologies. The results provide information on the likelihood of adoption, which allows for the comparisons as to which region or setting has a high or low relative likelihood for the adoption of new technologies.

Similar to the QAToCA tool, QATo-FT is structured under nine thematic areas (Table 1) with corresponding questions. Within each category, statements were assessed on a scale of $0-5$ (following the Likert scale) indicating the legitimacy (strength) of the suggested statement concerning their influence on the adoption potential for the case study area, where:

$0=$ not sure, has no positive effect on adoption likelihood (even negative);

$1=$ strongly disagree, has a limited positive effect on adoption;

2 = disagree;

$3=$ partly agree;

4 = agree;

5 = strongly agree, has a maximum positive influence on adoption likelihood;

$\mathrm{N}=$ if you think, the statement is not applicable in this case or appropriate.

Table 1. Thematic categories of QATo-FT.

\begin{tabular}{cl}
\hline Code & \multicolumn{1}{c}{ Thematic Areas of the Tool } \\
\hline A & Characteristics of forage technology (object of adoption) \\
B & Farm and household characteristics/constraints \\
C & Capacity of implementing institution \\
D & Attributes of dissemination strategy \\
E & Political/institutional framework at village level \\
F & Political/institutional framework at regional level \\
G & FT products and inputs market conditions \\
H & Perception of community towards FT \\
I & FT as an adaptation practice to climate change and other ecological benefits \\
\hline
\end{tabular}

Within each category, the aggregated agreements were translated into percentages showing the specific contribution of the set thematic category to the overall adoption potential for the targeted case study (with a maximum of $100 \%$ possible for each category) (see Supplementary Materials Tables S1 and S4 for the detailed questions and statements within the 9 thematic categories of the tool).

The tool was used specifically in (i) analysing the characteristic attributes of the innovation as an object of adoption, (ii) the capacity of support organisations, (iii) institutional conditions, (iv) markets and gender dynamics and (v) community perception on the adoption potential of forage technologies.

\subsection{Case Study Data}

The study took place in the villages of Ubiri, Lushoto and Mbuzii, Bumbuli, situated in the Tanga region of Northern Tanzania (Figure 1) and was part of a larger project 
on improved forages led by the International Centre for Tropical Agriculture (CIAT), Kenya [26]. The farmers of the participating villages (both for the interviews and the workshop) were part of innovation platforms. The farmers received improved forage grass species and planted them on designated parts of their farms. The area dedicated to these forages remained at the choice of each farmer. The innovation platforms aimed to facilitate learning through knowledge exchange between the participants and input from the participating researchers.

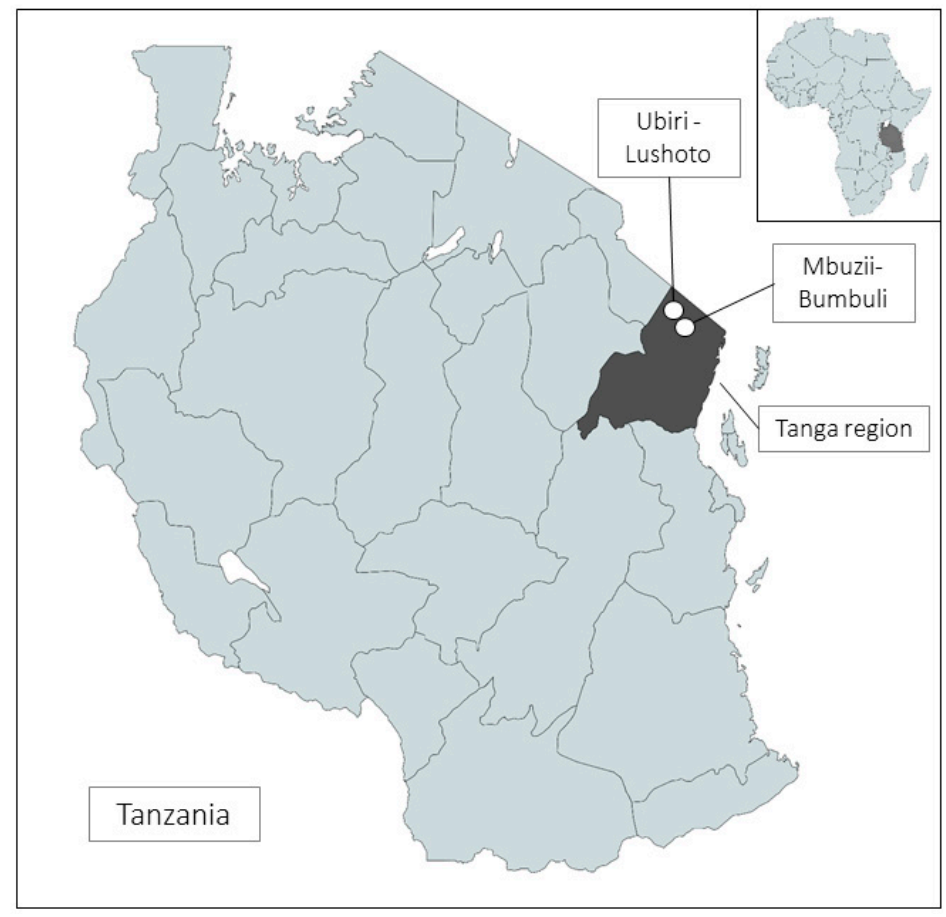

Figure 1. Case study location: two villages (Ubiri and Mbuzi(i)), the Tanga region, Tanzania.

During the field visits, a total of 20 farmer semi-structured interviews were conducted across the 2 case study villages (10 for Ubiri-Lushoto and 10 for Mbuzii-Bumbuli). The assessment workshop (a multi-stakeholder focus group discussion) based on the QATo-FT tool was attended by 35 participants from the extension, policy, farming (adopters and non-adopters), local authority, practitioners, technicians, service providers and research sectors. The farmers and extension staff from the two villages of Mbuzii and Ubiri were invited to this workshop, with most of them already belonging to innovation platforms formed under previous projects in this region. The entire workshop, which lasted for over $5 \mathrm{~h}$ (3/4 day), was guided by a mixed facilitation team consisting of external researchers and partners from a local research institution in the region. The results from the workshop were computed on-site, and the first draft results were presented for feedback, reflection and adjustment within the same workshop.

\section{Results}

In this subsection, the main findings are presented in two parts. Section 3.1 highlights the findings from interviews and field visits by specifically focusing on issues linked with the state of actual adoption in the targeted region, including the main motivating reasons for the initial adopting, and the general hindering and supporting factors for adoption based on the perspectives of the interviewed farmers. Section 3.2 focuses on the adoption potential (likelihood) of the region and general conditions that potentially contribute to this likelihood, based on the outcomes of the QATo-FT multi-stakeholder workshop. 


\subsection{Findings from Interviews and Field Visits}

\subsubsection{Main Triggering Factors to Initial Adoption}

The interviews unveiled the key triggering factors towards the initial adoption of forage technologies from individual farmers' perspectives. While the main triggering factors for adoption were both related to a shortage of feed and soil conservation problems, the expected economic advantages were not as dominant in the farmers' responses (Figure 2). The reasons for sustaining the practices of growing improved forages were stated as the year-round availability of fodder and increased fodder demand (due to higher livestock numbers) and accumulated benefits (e.g., increased animal numbers and forage yields). Soil conservation issues were mentioned less often as reasons for continuing with practice in contrast to their dominance as the main triggering factors (Figure 3). According to the farmers, up-scaling needs further provision of sufficient planting materials and the expansion of the programme to other farmers beyond the innovation platform. The variation in the importance of the triggering factors (especially land conservation) (Figure 2) and sustaining factors (e.g., constant availability of fodder) is an important lesson learnt from this survey (Figure 3).

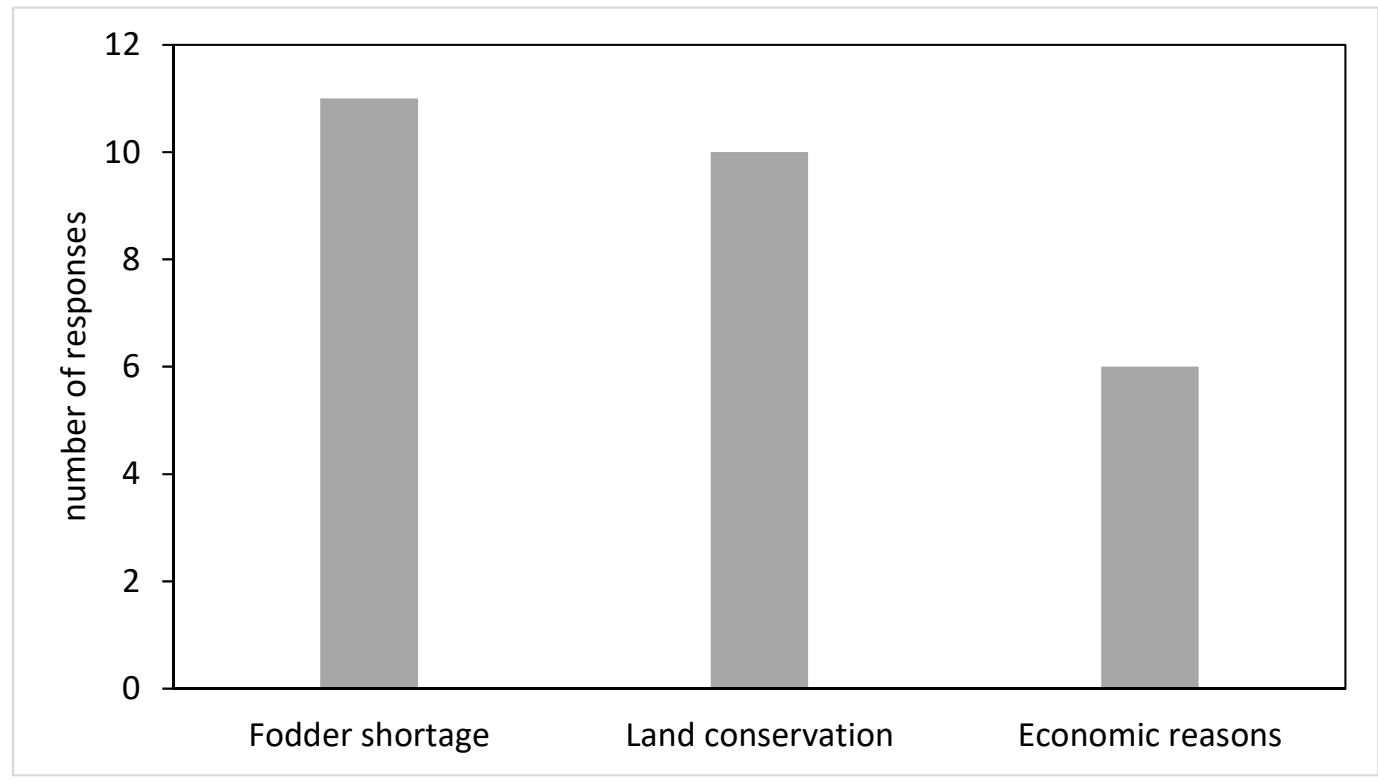

Figure 2. Main triggering factors for adopting forage tTechnologies; multiple responses possible $(n=20)$.

\subsubsection{Forage Production}

The interviewed farmers distinguished both the quality and quantity issues in their adoption decision process of forage technologies. In the dry season, the farmers noted the low quality of the available fodder sources, when no high-quality fodder was conserved. The lack of rainfall also leads to a shortage of forage quantities. Farmers have to walk long distances to fetch fodder from sites with a reasonable vegetation cover. Such sites could be along roads, hedges or river banks. Some farmers even feed banana stems to their livestock. The biomass of such sources was reported to be rather low. The long-distance between the farmstead and fodder collection areas leads to many hours spent on fodder collection. However, in the rainy season, farmers appreciate having high-quality forage grown close to the farmstead. The short distance to the cow sheds reduces the time of fodder collection from other sources, which can be better used on crop production. 


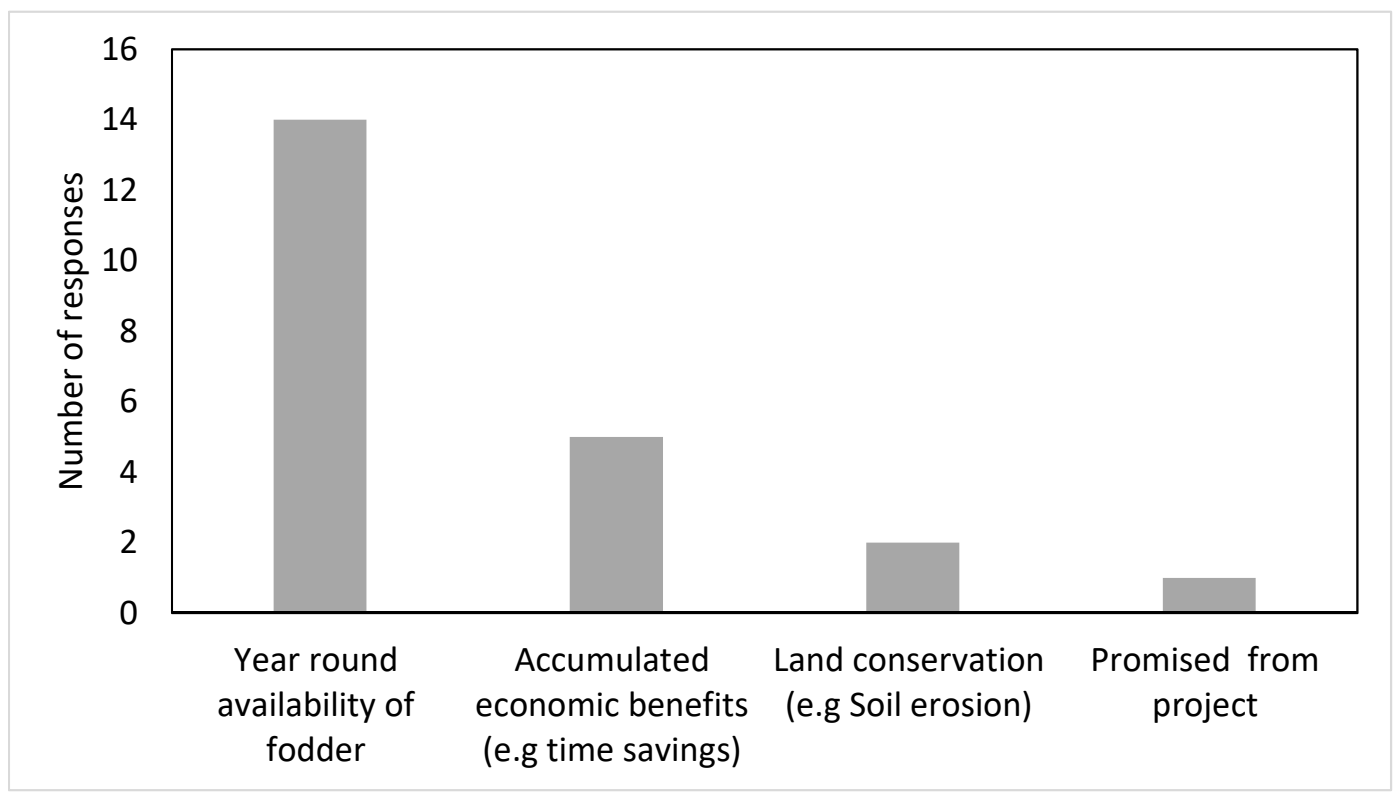

Figure 3. Reasons for sustaining the adoption of forage technologies; multiple responses possible $(n=20)$.

Farmers are aware of the higher quality of improved forage varieties but stress the low availability of planting material. Some farmers conserve forage harvested at the end of the rainy season. Even the ones who conserve forage (hay, silage) see it rather as an experiment than as a reliable source of livestock feed during the dry season. In general, forage production on slopes, both on the actual fields as well as on the field boundaries, is seen as a good way to control soil erosion.

\subsubsection{Organisational Issues within the Farm and Village Context}

Interviews with farmers on the organisational issues revealed the influence of both the innovation platform (IP) chairmen, village officers and extension officers. While the IP chairmen play a pro-active role in the promotion of forage production, knowledge distribution and the provision of planting material, the village officers are considered only as "not interfering", but not supportive to the actions of the farmers. The role of the extension officers depends on their engagement. Those in charge at the time of the interviews were seen as supportive and highly engaged. Generally, trust concerning the shared investments was low and some farmers hesitated to become members of the IPs, also based on reasons of not sufficiently trusting in the benefits of the shared learning and organisation among themselves (farmers). Nevertheless, the farmers' decision as individuals or as a group to adopt improved forages was accepted and respected by the entire community, and even led to some successful adopter farmers earning nicknames, such as "Mzee wa hay" in Swahili, which means "expert in making hay", or "Abzogani", meaning extension worker. This was a result of the exceptional skills of these farmers in managing improved forages. Their positive progress with adopting improved forages was found to be partly a result of the fact that they were generally engaged in entrepreneurial activities and had experience in general farm management, even before the introduction of improved forages.

\subsubsection{Summary Findings on Interviews and Field Visits}

The above findings show that the most important barriers to the adoption of improved forages for the targeted case study region are linked to the whole farming system and its wider environment, namely (a) the opportunity cost for labour is low during the dry season, so the labour savings from walking long distances for fetching low-quality fodder is not a primary objective for many farmers; (b) current breeds are not sufficiently high-yielding to 
justify the potential gains through improved forages; (c) the region is relatively cold, which leads to comparably slow growth of forages; (d) many farmers let forages grow to age with the intention to use them in times of scarcity (dry season) and do not cut them during the rains when other forages are also abundant, which leads to low quality forages being fed to the animals, resulting in undesired low milk yields; and (e) sufficient planting material, as well as extension advice on forage management and harvesting, is often not available.

\subsection{Findings from $Q A T o-F T$ Assessment}

\subsubsection{Adoption Potential}

The QATo-FT assessment for the two villages around Lushoto (Mbuzii and Ubiri) revealed a high but irregular influence of the various institutional thematic categories on the adoption potential for improved forages. The following paragraphs highlight those categories revealed by the workshop participants to be exerting a strong positive influence on adoption potential, as well as those identified as exerting a much lower or weaker influence on the adoption potential of improved forage technologies in the region.

The first positive category is the "community's perception towards forage technology" (H). It is assessed to have a strong supporting influence on adoption potential, especially for the case of Mbuzii, with a score of $100 \%$ (see Figure 4 ). This assessment implies that, so far, the ongoing forage project activities are viewed positively and as not interfering in any way with the economic activities of the non-adopters in the region. While non-adopters are not as close to the innovation as adopters, they respect the decision of those who have chosen to adopt the technology and, for them, their daily economic activities are not negatively affected just for the simple reason of not having adopted the technology. Adopters and non-adopters, therefore, can live side by side in the same community, which leaves a chance for scaling up in the future, once non-adopters start observing the benefits emerging from adopters as a result of their new practice. In addition, the promoting organisations for improved forages in the area (i.e., mainly TALIRI Tanga), as well as the extension officers, are working closely with village leaders of the community. Although the village leaders accept, recognise and do not interfere with forage promotion activities, they are not actively supportive. Young farmers showed a high willingness to participate in the forage technology project activities. They acknowledge that improved forage technology practices create employment opportunities for them, although livestock farming in this area predominantly remains an activity for the elderly.

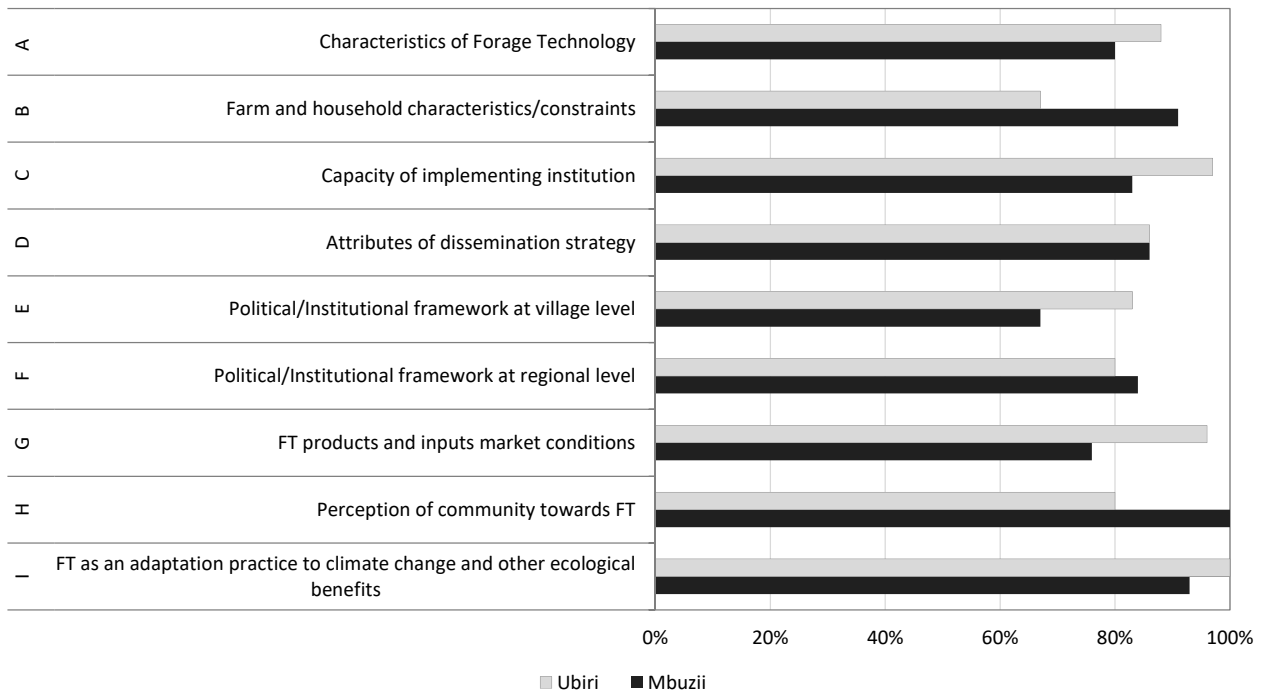

Figure 4. Thematic influence on adoption potential for the two villages in the case study region: Mbuzii-Bumbuli and Ubiri-Lushoto. 
Under the category "Knowledge on effect of FT as an adaptation practice to effects of climate change and other ecological benefits", factors such as soil conservation were discussed as having a strong positive influence on adoption potential, especially for Ubiri village (100\% agreement). The role of forages in controlling soil erosion on slopes seems to be well known to most farmers in the region. Crop farmers could be seen planting forages in the contours within or as hedges around their farms. As the main priority for such farmers is crop production, initially, the output from these forages within or around their fields is handed over to livestock farmers in the village. However, crop farmers quickly realised the additional benefit once they diversified production (i.e., engaging in livestock production in addition to crop production). This is reflected in the results of our field interviews, where farmers mentioned that adopting the cultivation of improved forages was not only performed to prevent soil erosion but equally to produce fodder. Such a mixed farming system is working quite well in the region, especially as "zero grazing" is the main livestock practice. In this way, forages from the contours and crop residues after harvest are cut-and-carried home for feeding the animals especially in the dry season when there is a shortage of forage from public feeding areas.

In summary, the results of the QATo-FT workshop reveal that, for the case of MbuziiBumbuli (Figure 4), (i) the receptive nature of the community towards the technology (100\% agreement) and (ii) the expectations of improved forages on the ecological benefits (93\%) have a strong positive influence on the adoption potential for improved forages. For the case of Ubiri-Lushoto (Figure 4), the (i) expectations of improved forages on the ecological benefits (100\%), (ii) the role of promoting institutions (97\%) and (iii) the products and input market conditions around livestock production and improved forages (96\%) positively influence the adoption potential for this village. On the other hand, the categories exerting a much weaker influence on the adoption potential for the two villages, which need to be considered in any further promotion, includes (i) the political and institutional framework at the regional level (67\%), (ii) products and input market conditions (76\%) for Mbuzii-Bumbuli and iv) farm/household characteristics (68\%) for Ubiri-Lushoto.

\subsubsection{Specific Supporting and Hindering Factors}

Looking at specific statements within each of the categories assessed, the workshop participants for Mbuzii and Ubiri revealed both the strong hindering and weak hindering factors of the adoption potential for the two villages (Table 2). These factors can be considered as limiting in any promotional attempt geared towards boosting the adoption of the innovation beyond the present state in Lushoto (for detailed information on the supporting factors, see Supplementary Materials Tables S2 and S3).

Table 2. Strong and weak hindering factors for the adoption of improved forage technologies ${ }^{1}$.

Village

Mbuzii-Bumbuli

Ubiri-Lushoto
Weak Hindering Factors

Household labour is usually sufficient to implement FT (A2)

The local government promotes FT adoption through extension programmes (E3)

The majority of farmers have knowledge of FT or traditional/indigenous knowledge similar to FT (B2)

Young farmers are willing to participate in FT project activities, and FT practice creates employment opportunities for them (H3)
Strong Hindering Factors

The promoting organisation promotes FT through mass media, such as radio, TV or newspapers (D9)

There exist decentralised structures within the administration, which allow locally adapted and timely solutions to farmers' problems (E5)

There is a local government with strong leadership that commits itself to development objectives (F1)

The promoting organisation promotes FT through mass media, such as radio, TV or newspapers (D9)

The settlement pattern allows extension officers easy access to farmers for promotional purposes (F5)

${ }^{1}$ Strong hindering factors: ranked with 1 on a scale of $1-5$, i.e., the participants strongly disagree with the assumption, which implies the aspect has a strong limiting effect on adoption for the region. Weak hindering factors: ranked with 2, i.e., participants disagree with the assumption, which implies the aspect has a limiting effect on adoption for the region. 
In summary, across both the villages, the following strong hindering factors of the effective adoption potential were revealed by the QATo-FT assessment: (i) communication channels used in transferring messages to potential adopters, (ii) the system of administration practised in the region, which is less decentralised for timely solutions to the farmer's needs, (iii) the indifference of local-level governance structures to issues of forage technology and (iv) accessibility challenges to the extension officers, which affects effective dissemination campaign activities. These findings tally with those from field observations, as highlighted above.

\section{Discussion}

The above findings reveal a shortage in animal feed and the need for soil conservation as the main triggers of the initial adoption of improved forages by the interviewed farmers in the Tanga region. Furthermore, the possibility for the year-round availability of fodder was observed as the main reason for sustaining the practices after adoption. Such findings correspond with those of Habtemariam [23] and Hansen [24], who highlighted the possible mitigating role of especially land-based related technologies against the effects of climate change as a determining factor for smallholder farmers' adoption decisions. The authors further added that a climate-risk related adoption decision could be especially true for farmers perceived to have experienced past production shocks as a result of less certainty in climate patterns.

With regard to the hindering factors, "low opportunity cost for labour in the dry season" has been identified as a major hindering factor to wider forage technology adoption in the case study area. This finding is in line with that of Fowler and Rockstrom [22], who remarked that the favourable conditions for technology adoption by the smallholder farmers require a low effect on the peak labour demands. Farmers grow only as much forage as needed for the cropping season. This needs to be observed in the light of seasonal changes in the opportunity costs of labour. During the cropping season with high opportunity costs of labour, close-by grown forages are appreciated for the easy supply of fodder, while during the dry season with low opportunity costs of labour, farmers rather use the time for walking long distances to fetch low-quality forage, despite their low nutrient content and corresponding negative effects on milk yields. The absence of off-farm activities does not offer any other income, but rather allows for the opportunity to dedicate more farmland to cash crops instead of forages.

Moreover, the absence of sufficient planting material, as well as the limited extension advice on forage management and harvesting, has been indicated as a hindering factor to adoption. In particular, the latter (i.e., weak extension and advisory service support) has only helped to reinforce the problem of trust concerning the shared investments in the region with some farmers hesitating to become members of innovation platforms, which was also based on reasons of not sufficiently trusting in the benefits of shared learning and organisation among themselves. These findings correspond to those of Straub [19], who stated that successfully facilitating technology adoption must address the cognitive and contextual concerns of the individual farmers.

Based on these factors and irrespective of the high adoption potential for forage, as revealed in the QATo-Ft findings above, we suggest that an integrated sustainable livelihood approach is needed to bridge this gap between the potential and actual adoption levels for the region. In particular, revisiting the farmers' regard for time (through other profitable off-farm activities) can create the need for growing improved forages. Overall, as preconditions to raise the actual adoption levels for the Tanga region, this study calls for more targeted efforts in the domains of knowledge transfer, administration, economics and agronomy, as specified in Table 3. 
Table 3. Recommended domains for improvement and related activities.

Domains

Knowledge transfer

Administrative

Economic

Agronomic

\section{Specific Activities}

Sensitisation and education of farmers on short and long term benefits of introduced forage technologies towards general livestock production, increased milk yield and soil conservation, alongside other ecological benefits.

Ensure the existence of decentralised structures within the administration, which allow for locally adapted and timely solutions to the farmers' problems. Allocate a budget for extension officers to be able to move around the farmers and attend to the farmers' needs.

Form and strengthen solid partnerships between local governments, farmers, NGOs, service providers, extension officers and all other beneficial networks around the practice of improved forages beyond the present existing innovation platforms in the region.

Organise easy access to basic resources, such as water at the community level, to serve the farmers, especially in dry seasons.

Improve off-farm income possibilities to reduce pressure on land use as the only income source.

Create access to the existing markets to encourage the mass production of milk from farmers, which

will consequently trigger their adoption of improved forages, e.g., establishing more local collection centres endowed with small milk cooling facilities with the possibility of direct pick up at the farm gate

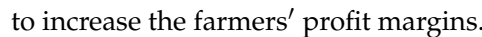

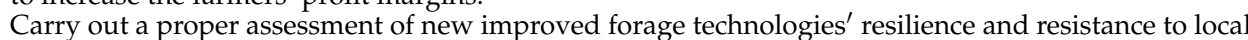
and possible changing climatic factors of the region.

Improve the issue of accessibility to seeds or planting material for potential adopter farmers who have become convinced of the stimulating effect of improved forages on their milk yield levels, e.g., the accessibility to planting materials should not be limited only to members of the innovation platforms, but open even to non-members who show an interest.

\section{Conclusions}

Our study focused on the up-scaling potential and the adoption of improved, more nutritive and productive forages by smallholder farmers. We systematically identified and analysed the role of (i) institutional and political, (ii) socio-economic and (iii) cultural factors towards influencing the adoption and diffusion of improved forage technologies in SSA, with a focus on a smallholder farming community in the Tanga region of Tanzania. The findings show that the most important barriers to adoption are linked to the whole farming system and its wider environment, namely the low opportunity cost for labour in the dry season; the local cattle breeds that are not efficiently profiting from improved forage qualities, but rather lack sufficient amounts of water and feed; the region's cool climate, which leads to the comparably slow growth of forages; low maintenance leading to lowquality forage being fed, which might not result in the desired milk yield; sufficient planting material, as well as the extension advice on forage management and harvesting, is often not available; and the low milk prices provide low incentives for efficient milk production.

The QATo-FT assessment revealed a high adoption potential based on the general receptive nature of the community, the expectations towards improved forages providing ecological benefits and the role of promoting institutions as the main supporting factors. Nevertheless, the political and institutional framework at the regional level as well as the market conditions are assessed to have a weaker influence on the adoption potential for the region. This is complemented by the lack of off-farm income possibilities for the region leading to low opportunity costs for labour (especially during dry seasons).

As our study is predominantly qualitative, relying on a small sample size across two villages, we acknowledge the fact that a wide quantitative survey and or long ethnographic studies across a large sample area (involving many villages) might have been more representative. Nevertheless, based on our findings, we recommend more socioeconomic and agronomic research towards contributing to better integrated approaches for the region, in order to bridge the gap between actual and potential adoption. Specifically, more attention should be focused on the options for providing off-farm income opportunities, allowing for the more efficient use of land and labour and introducing more climate resilient and resistant improved forage technologies, all efforts for further promoting the adoption of improved forages among this farming community. By doing so, the performance of existing heads of cattle for the region will be improved, milk yields would increase and eventually farmers' income levels would be enhanced. As a final impact, this can improve nutrition and, eventually, contribute to poverty alleviation in the case study region. 
Supplementary Materials: The following supporting information can be downloaded at: https:/ / www.mdpi.com/article/10.3390/agronomy12020305/s1, Table S1: QATO-FT statements per category; Table S2: overall supporting forces to forage adoption potential Mbuzii village; Table S3: overall supporting forces to forage adoption potential Ubiri village and Table S4: QATO-FT results per village; scoring values per statement.

Author Contributions: Conceptualisation, H.T.N. and J.S.; methodology, H.T.N. and J.S.; software, H.T.N. and J.S.; validation, H.T.N., P.Z. and B.K.P.; formal analysis, H.T.N. and J.S.; investigation, H.T.N., B.N. and J.S.; resources, W.M., R.M. and R.L.; writing-original draft preparation, H.T.N., J.S. and V.N.N.; writing-review and editing, P.Z., J.S. and H.T.N.; visualisation, J.S.; supervision, B.K.P.; project administration, B.K.P.; funding acquisition, B.K.P. All authors have read and agreed to the published version of the manuscript.

Funding: This work received financial support from the German Federal Ministry for Economic Cooperation and Development (BMZ), commissioned and administered through the Deutsche Gesellschaft für Internationale Zusammenarbeit (GIZ) Fund for International Agricultural Research (FIA), grant number: C-151-15 ("Potential farm to landscape impact and adoption of forage technologies in smallholder dairy production systems in Tanzania"). The research was undertaken as part of the CGIAR Research Program on Livestock, which is supported by contributors to the CGIAR Trust Fund. CGIAR is a global research partnership for a food-secure future. Its science is carried out by 15 research centres in close collaboration with hundreds of partners across the globe. ETH Zurich, Group of Plant Nutrition, supported the MSc field work.

Institutional Review Board Statement: Not applicable.

Informed Consent Statement: Informed consent was obtained from all subjects involved in the study.

Data Availability Statement: All data is provided under Supplementary Materials.

Acknowledgments: We warmly thank the workshop participants from the villages of Mbuzii and Ubiri, including the regional livestock extension officers for their support, engagement and wealth of insights and information. Thanks to Venance Kengwa (CIAT driver and field technician-Arusha office) who professionally took care of our transportation during our field visits to Lushoto, accompanied us for farm visits and farmers' interviews and provided valuable insights during the discussions. We thank An Notenbaert (CIAT, Kenya) for the time allocated in proof reading and carrying out a technical check of the project report that this paper is based on. Last but not the least, we thank the team from TALIRI (Tanzanian Livestock Research Institute) in Tanga and a livestock district officer for joining the QATo-FT workshop, supporting us as facilitators and ensuring a lively inter-action during the workshop by iteratively translating the farmers' discussions from Swahili to English and, hence, ensured a better assimilation.

Conflicts of Interest: The authors declare no conflict of interest.

\section{References}

1. Ndambi, O.A.; Hemme, T.; Latacz-Lohmann, U. Dairying in Africa-Status and recent developments. Livest. Res. Rural. Dev. 2007, $19,25$.

2. Otte, M.J.; Chilonda, P.C.; Ruminant, S. Production Systems in Sub-Saharan Africa: A systematic Review; Food and Agriculture Organization of the United Nations: Rome, Italy, 2002.

3. Jahnke, H.E.; Tacher, G.; Keil, P.; Rojat, D. Livestock Production in Tropical Africa, with Special Reference to the Tsetse-Affected Zone. In Livestock Production in Tsetse-Affected Areas of Africa, Nairobi, Kenya, 1987; International Livestock Centre for Africa and the International Laboratory for Research on Animal Diseases: Nairobi, Kenya, 1987; pp. 3-21.

4. Zamani, O.; Pelikan, J.; Schott, J. EU Exports of Livestock Products to West Africa: An Analysis of Dairy and Poultry Trade Data; Thünen Working Paper; Thünen-Institut: Braunschweig, Germany, 2021.

5. Smith, J.; Tarawali, S.; Grace, D.; Sones, K. Feeding the World in 2050: Trade-offs, synergies and tough choices for the livestock sector. Trop. Grasslands-Forrajes Trop. 2013, 1, 125. [CrossRef]

6. Lukuyu, B.; Kitalyi, A.; Franzel, S.; Duncan, A.; Baltenweck, I. Constraints and Options to Enhancing Production of High Quality Feeds in Dairy Production in Kenya, Uganda and Rwanda ICRAF Working Paper No. 95; Center for International Forestry Research (CIFOR) and World Agroforestry Centre (ICRAF): Nairobi, Kenya, 2009.

7. Alexandratos, N.; Bruinsma, J. World Agriculture towards 2030/2050: The 2012 Revision; ESA Working Paper No. 12-03; FAO: Rome, Italy, 2012. 
8. Gillah, K.A.; Kifaro, G.C.; Madsen, J. Urban and peri urban dairy farming in East Africa: A review on production levels, constraints and opportunities. Livest. Res. Rural. Dev. 2012, 24, 198.

9. Sumberg, J. Constraints to the adoption of agricultural innovations: Is it time for a re-think? Outlook Agric. 2005, 34, 7-10. [CrossRef]

10. Njarui, D.M.G.; Kabirizi, J.M.; Itabari, J.K.; Gatheru, M.; Nakiganda, A.; Mugerwa, S. Production characteristics and gender roles in dairy farming in peri-urban areas of Eastern and Central Africa. Livest. Res. Rural. Dev. 2012, $24,2012$.

11. Wambugu, C.; Place, F.; Franzel, S. Research, development and scaling-up the adoption of fodder shrub innovations in East Africa. Int. J. Agric. Sustain. 2011, 9, 100-109. [CrossRef]

12. Franzel, S.; Wambugu, C. The uptake of fodder shrubs among smallholders in East Africa: Key elements that facilitate widespread adoption. In Forages: A Pathway to Prosperity for Smallholder Farmers, Thailand, 2007; Hare, M.D., Wongpichet, K., Eds.; Ubon Ratchathani University: Ubon Ratchathani, Thailand, 2007; pp. 203-222.

13. Ngwira, A. Forage demand and constraints to adoption of forage technologies by livestock keepers in Malawi. Trop. Grassl. 2003, 37, 274-278.

14. Gebremedhin, B.; Ahmed, M.M.; Ehui, S.K. Determinants of adoption of improved forage technologies in crop-livestock mixed systems: Evidence from the highlands of Ethiopia. Trop. Grassl. 2003, 37, 262-273.

15. Mwangi, D.M.; Wambugu, C. Adoption of forage legumes: The case of Desmodium, intortum and Calliandra, calothyrsus in central Kenya. Trop. Grassl. 2003, 37, 227-238.

16. Ndah, H.T.; Schuler, J.; Nkwain, V.N.; Nzogela, B.; Mangesho, W.E.; Mollel, R.; Loina, R.; Paul, B.K. Factors Affecting the Adoption of Forage Technologies in Smallholder Dairy Production Systems in Lushoto, Tanzania; CIAT Working Paper; CIAT: Cali, Columbia, 2017.

17. Ndah, H.T.; Knierim, A.; Ndambi, O.A. Fish Pond Aquaculture in Cameroon: A Field Survey of Determinants for Farmers' Adoption Behaviour. J. Agric. Educ. Ext. 2011, 17, 309-323. [CrossRef]

18. Rogers, E.M. Diffusion of Innovation; The Free Press: New York, NY, USA, 1995.

19. Straub, E.T. Understanding Technology Adoption: Theory and Future Directions for Informal Learning. Rev. Educ. Res. 2009, 79, 625-649. [CrossRef]

20. Ndah, H.T.; Schuler, J.; Uthes, S.; Zander, P.; Triomphe, B.; Mkomwa, S.; Corbeels, M. Adoption Potential for Conservation Agriculture in Africa: A Newly Developed Assessment Approach (QAToCA) Applied in Kenya and Tanzania. Land Degrad. Dev. 2015, 26, 133-141. [CrossRef]

21. Adesina, A.A.; Baidu-Forson, J. Farmers' perceptions and adoption of new agricultural technology: Evidence from analysis in Burkina Faso and Guinea, West Africa. Agric. Econ. 1995, 13, 1-9. [CrossRef]

22. Fowler, R.; Rockstrom, J. Conservation tillage for sustainable agriculture: An agrarian revolution gathers momentum in Africa. Soil Tillage Res. 2001, 61, 93-108. [CrossRef]

23. Habtemariam, L.T.; Gandorfer, M.; Kassa, G.A.; Sieber, S. Risk experience and smallholder farmers' climate change adaptation decision. Clim. Dev. 2019, 12, 385-393. [CrossRef]

24. Hansen, J.; Hellin, J.; Rosenstock, T.; Fisher, E.; Cairns, J.; Stirling, C.; Lamanna, C.; van Etten, J.; Rose, A.; Campbell, B. Climate risk management and rural poverty reduction. Agric. Syst. 2018, 172, 28-46. [CrossRef]

25. Probst, L.; Ndah, H.T.; Rodrigues, P.; Basch, G.; Coulibaly, K.; Schuler, J. From adoption potential to Transformative Learning around Conservation Agriculture. J. Agric. Educ. Ext. 2018, 25, 25-45. [CrossRef]

26. Paul, B.K.; Groot, J.C.; Maass, B.L.; Notenbaert, A.M.; Herrero, M.; A Tittonell, P. Improved feeding and forages at a crossroads: Farming systems approaches for sustainable livestock development in East Africa. Outlook Agric. 2020, 49, 13-20. [CrossRef] 